\title{
EDUCAÇÃO KAINGANG E EDUCAÇÃO ESCOLAR KAINGANG: UM EXEMPLO DE BEM ESTAR E BEM VIVER
}

IVONE JAGNIGRI DA SILVA ${ }^{1}$

UFRGS, BRASIL

https://orcid.org/0000-0003-0860-2199

SÉRGIO ROBERTO KIELING FRANCO ${ }^{2}$

UFRGS, BRASIL

http://orcid.org/0000-0002-1221-1310

\begin{abstract}
RESUMO: Este artigo analisa as possibilidades da escola indigena kaingang no encontro das culturas indigena e não indígena a partir da experiência da comunidade Taquarucu na escola indígena Katiu Gria. A partir da observação direta e de depoimentos colhidos, observa-se que a escola constitui uma fonte hegemônica de conhecimento para essas crianças, que também aprendem através de outras situações vivenciadas por elas, especialmente através da participação nas atividades cotidianas junto a familiares, fortalecendo a cultura kaingang. Ao reconhecer alguns aspectos comuns dos processos de aprendizagem nesses dois contextos (indígena e não indígena), como a experiência e a participação de todos, a atenção aos esforços da prática do conhecimento, na iniciativa dos aprendizes, e a atribuição progressiva de responsabilidades, o artigo procura contribuir para os debates sobre o processo da educação nos espaços significativos para a comunidade e a preservação da cultura kaingang.
\end{abstract}

PALAVRAS-CHAVE: Kaingang, Escola indígena, Cultura indígena, Integração escolacomunidade

ABSTRACT: This article analyzes the possibilities of the Kaingang indigenous school in meeting indigenous and non-indigenous cultures based on the experience of the Taquarucu community at the Katiu Gria indigenous school. From direct observation and testimonies collected, it is observed that the school is a hegemonic source of knowledge for these children, who also learn through other situations experienced by them, especially through participation in daily activities with family members, strengthening the kaingang culture. By recognizing some common aspects of the learning processes in these two contexts (indigenous and non-indigenous), such as the experience and participation of all, attention to the efforts of knowledge practice, in the initiative of apprentices and the progressive attribution of responsibilities, the article seeks to contribute to the debates on the education process in spaces that are significant to the community and the preservation of Kaingang culture.

KEYWORDS: Kaingang, Indigenous school, Indigenous culture, School-community integration

\footnotetext{
${ }^{1}$ Mestranda em Educação pela Universidade Federal do Rio Grande do Sul. E-mail: jagnigri@gmail.com

${ }^{2}$ Professor do Programa de Pós-Graduação em Educação da UFRGS. E-mail: sergio.franco@ufrgs.br
} 


\section{Introdução}

Os Kaingang são um dos maiores povos indígenas em tamanho populacional no Brasil. Segundo os dados do IBGE 2010, eles somam 37.470 pessoas, das quais 31.814 vivem em Terras Indígenas (IBGE, 2020). A maioria das terras indígenas possui escolas onde suas crianças aprendem a ler e escrever. Mas isso não quer dizer que eles foram totalmente dominados pelo modelo de ensino não indígena. Atualmente, além da escola, os kófa (anciãos) são uma referência para revitalizar o conhecimento cultural tradicional nas comunidades, dentro da terra indígena. Mas a escola também é um centro de atenção das famílias de uma comunidade pelo modo de atender a clientela. Elas trabalham de forma coletiva, de modo que os professores, os kófa e os pais dos alunos, têm o objetivo de dar continuidade ao conhecimento kaingang, reforçando a educação tradicional de seus ancestrais, assim como a educação escolar para formação das crianças com conhecimento além disso, com um olhar mais amplo em relação ao mundo ao seu redor. É sobre esse modo de ensino e a convivência dos costumes próprios que trataremos neste artigo.

Sabemos que o período colonial foi um dos momentos mais marcantes quanto ao aparecimento da educação escolar, por meio dos missionários jesuítas, com intuito de catequizar os índios através da religião católica, criando assim uma barreira para a prática dos conhecimentos tradicionais desse povo. Foi muito grande o impacto desse modelo de educação que trouxeram. Mas também houve muita resistência por essa sociedade que hoje, em suas Terras Indígenas, usa e usufrue das riquezas de conhecimento de suas raízes, como está garantido na Constituição Federal.

Este artigo é derivado de uma pesquisa no campo da Educação (SILVA, 2020). O objetivo é analisar a educação tradicional, nos costumes kaingang, e a escola indígena kaingang, tendo como referência a comunidade do Setor Vãgvãsa-Taquaruçu, na Terra Indígena Guarita. Conhecendo e conversando com as pessoas neste Setor, percebemos algo diferente, que chamou nossa atenção ${ }^{3}$. O modo de viver das pessoas moradoras do local, o cotidiano das famílias em suas moradias simples, o contato com a natureza das crianças e jovens. A forma como eles educam suas crianças demonstra uma marca muito forte do modo tradicional kaingang.

No entanto, a educação escolar também se mostrou bem avançada quanto à frequência das crianças e jovens, assim como a aprendizagem. Os professores que trabalham naquela escola estavam envolvidos com planejamentos diferenciados voltados à realidade local, mas sempre comparando com os acontecimentos regionais, nacionais e mundiais. As aulas são integradas entre as atividades teóricas e práticas de seus costumes como alimentação, confecção de artesanatos, aula de campo

\footnotetext{
${ }^{3}$ A pesquisadora que fez o trabalho de campo é do povo Kaingang, mas de outra comunidade.
} 
para observação do meio em que vivem e também a visitação dos kófa da comunidade.

Dessa forma, as crianças e jovens acompanham as transformações nos ambientes e são incentivados a respeitar, preservar o que é importante na cultura deles. As aulas, além de se ocuparem da alfabetização nas duas línguas, acontecem através de visitas aos kófa para entrevistá-los, permitir que contem histórias ou conversem com os estudantes. Os professores indígenas trabalham diretamente em contato com o conhecimento das pessoas mais antigas do local. Também os não indígenas, que atuam naquela escola, estão envolvidos nessa forma de educação.

Quanto à prática da educação nas famílias, em casa, as crianças e jovens são levados a obedecer as normas a eles passadas, como respeito aos mais velhos, respeito à natureza e seus componentes, preparação da lavoura para o plantio, fazer pequenas plantações, além de coletar os elementos na natureza para mantimento. Com isso, são ensinados a cuidar e conservar a natureza.

A diferença que a comunidade demostra pode ser entendida relacionando-se com o pensamento de Paulo Freire, em seu livro Pedagogia do Oprimido, quando este aponta que a aprendizagem acontece por meio da dialogicidade, da troca de experiências e saberes (FREIRE, 2018). Dessa maneira que as pessoas vão sendo educadas e se educam. O ensino acontece no espaço de cada família e também na convivência da comunidade, além da observação do espaço em que vivem. A aprendizagem se constrói porque os jovens estão desenvolvendo a prática dos conhecimentos a eles passados pelos seus pais, avôs, avós e lideranças.

Dar continuidade aos costumes e revitalização da cultura, através do trabalho pedagógico diferenciado da escola indígena é escolha deles. Destaca-se que os pais são atuantes, participantes na construção dos planejamentos, do calendário e dos conteúdos a serem desenvolvidas para o ano letivo. Além disso, a comunidade escolar, a liderança, os conselheiros, que são os kófa, estão sempre acompanhando a escola, contribuindo com seus conhecimentos.

A língua falada pelas famílias da comunidade é unicamente a língua kaingang. As crianças e os jovens se comunicam através da própria língua, tanto na escola como também no cotidiano. Sente-se a essência do bem viver e do bem-estar, uma segurança no meio daquelas pessoas através das palavras que transmitiam nos relatos. Trata-se de uma comunidade verdadeiramente kaingang.

Percebemos o papel dos kófa, com sua importância para o processo da educação, do modo de ensinar e dos ensinamentos. Eles são a peça fundamental para essa função, além da escola. Trata-se da educação passada à nova geração. Em outro estudo (SILVA, 2020), colhemos um depoimento que denota a importância dessa atitude: "Hoje eles (os kófa) são por onde que buscamos o saber, são a nossa fonte de pesquisa, pois sabem tudo que é o bem viver dentro da cultura. São os grandes kaijró mág, conhecedores nos quais se buscam os ensinamentos, tanto 
crianças, jovens ou adultos." A mesma ideia é destacada por Bruno Ferreira

Falar com pessoas mais velhas de nossa comunidade é uma viagem ao passado, se aventurar na tradição que está muito presente nas ações que essas pessoas praticam, seja ela a mais simples recepção em suas casas até as mais complexas narrativas, que é a história de vida do seu povo. Aprender a ouvir, respeitar o tempo e o espaço durante a conversa. (FERREIRA, 2014, p. 21).

Os vẽnhkajrãn (ensinamentos) e os juvãn (conselhos) eram e são a parte feita por eles. Por isso, um dos fatos de destaque naquela comunidade é perceber que o processo da educação tradicional e a educação escolar estão juntas. Uma complementa a outra de modo a não afastar as crianças de seus costumes e, principalmente, da mata. Além disso, os professores também trabalham os fatos, os acontecimentos do nosso país, para além da Terra Indígena. Eles assistem a vídeos e documentários, para acompanhar o que acontece fora de seu espaço. Entendem que isso faz parte da vida em sociedade não indígena na atualidade. Assim, a tecnologia também está bem presente no cotidiano das escolas indígenas e das famílias. Não há como se afastar dessa realidade, mas trabalhar com isso de forma que seja um benefício para a comunidade.

Buscamos, dessa forma, conhecer melhor e com mais clareza, a educação kaingang, aquela dada pelos nossos avôs e avós que nos prepara para vida dentro da cultura, mas também intentamos compreender a relação desta educação tradicional e dos costumes tradicionais com a educação escolar indígena. Em que momento ou até onde a escola está envolvida com esses conhecimentos em sua metodologia de trabalho, seus planejamentos junto aos professores e aos alunos.

Para conseguir as informações buscadas, utilizamos uma metodologia que pudesse permitir que se manifestassem, sem assustálos, mas com muita cautela, usando a fala. Nesse caso, desenvolvemos a pesquisa de campo através de visitas à comunidade, conversando com as pessoas, crianças, jovens, kófa, em língua Kaingang, de forma que fosse um compartilhamento de ideias e questionamentos sobre o assunto em estudo. Muitas vezes utilizamos a palavra jamré (cunhada), régre (prima), considerando o costume tradicional kaingang.

Em pesquisa recente, já citada (SILVA, 2020), um dos entrevistados deixa claro a ideia de considerar os parentes dentro da cultura. Assim, ele diz que

o aprendizado dentro da educação tradicional kaingang se mostra através do comportamento social onde os jovens kanhgág aprendem a considerar seus parentes, jamré (cunhados e cunhadas), inh mén (marido), inh prũ (esposa), kakrẽ (sogro), má (sogra), régre (primo/prima), mré ke (irmãs/irmãos consanguíneos), 
jóg sĩ (tio mais novo), jóg kófa (tio mais velho) nỹ kófa (tia mais velha), nỹ sĩ (tia mais nova), e assim por diante, respeito a sua marca contrária para formação das novas famílias e assim ampliando o parentesco kamẽ e kanhukrẽ ${ }^{4}$, além disso, respeitando os sanh há (mais velhos) os kófa (velhos), os pã'i (lideranças), são práticas de respeito e reciprocidade porque eles sempre estarão prontos para se ajudarem em qualquer situação (SILVA, 2020, p.42).

Para o presente artigo, acompanhamos também alguns trabalhos dos professores na escola (fomos bem recebidos pela direção da escola e pelos professores). Participamos de brincadeiras com os alunos, pois são bem interativos e não estranharam a nossa presença. Isso ajudou muito para dialogar com eles. Fizemos também entrevistas com alguns professores indígenas que atuam na escola.

Ficou-nos claro que a educação, no costume kaingang, acontece no contexto social em que se vive, dispensando o acesso à escrita e aos conhecimentos universais, pois cada sociedade possui uma forma própria e tradicional de educação caracterizada pela transmissão oral do saber socialmente valorizado.

\begin{abstract}
A tradição e a perpetuação dos conhecimentos ancestrais perpassaram séculos e ainda continuam, através dos tempos, vivos entre as gerações atuais, sendo especialmente transmitidas pela oralidade. A palavra, para os Kaingang, tem valor de respeito, sentido de vida, de existência, de compromisso, de comunicação. A vida acontece no universo das expressões, interações e comunicações entre os sujeitos, conforme a cosmologia Kaingang (FREITAS, 2017, p. 39).
\end{abstract}

É dessa forma, para além da escola, não se dando apenas na transmissão oral, mas também no aprender a fazer na prática, através de observações diárias das crianças e professores em seu entorno.

Por outro lado, educação escolar kaingang é uma forma sistemática e específica de implementar a escola entre as comunidades de maneira que, a partir das formas de construção do conhecimento propriamente kaingang, possa-se ter acesso aos outros conhecimentos sistematizados pela escola nos conteúdos curriculares que, por sua vez, pressupõe o uso da escrita, além de se articular de maneira reflexiva ao contexto sociocultural. O Referencial Curricular Nacional para as Escolas Indígenas apresenta características específicas, dando ênfase para o aspecto comunitário das escolas, uma vez que é conduzida pela comunidade, de acordo com seus projetos, suas concepções e seus princípios. Isto se

\footnotetext{
${ }^{4}$ Um dos aspectos importantes destes costumes está relacionado à organização sócio-cosmológica das metades: Kamẽ e kanhrukrẽ que estabelece as relações sociais, a reciprocidade e de cooperação mútua entre o grupo. E as pessoas mais velhas continuam ensinando a importância de se preservarem estas relações entre as metades para formação da família.
} 
refere tanto ao currículo quanto aos modos de administrá-lo. Inclui possibilidades de organização quanto ao calendário escolar, aos procedimentos pedagógicos, aos conteúdos e ao uso do espaço escolar. (BRASIL, 1998). Neste sentido, não é uma questão nem de incorporação, por parte dos kaingang, dos conhecimentos da sociedade não indígena, tampouco de adaptação dos conhecimentos da sociedade não indígena ao contexto sócio-cultural, mas sim de construção conjunta de um saber intercultural, que seria a construção de uma proposta pedagógica baseada na maneira como eles veem o mundo, com o uso da sua língua materna em seus processos de ensino e aprendizagem.

\section{Escola Indígena Katiu Gria}

O nome da escola na comunidade é Escola Estadual Indígena de Ensino Fundamental Katiu Gria. Este nome foi escolhido pela comunidade em homenagem ao primeiro morador deste local, segundo pesquisa dos próprios professores. A construção é um prédio de alvenaria de cor branca e marrom. As crianças demonstram gostar muito do local. É uma típica escola. Funciona assim como uma escola não indígena, mas os alunos são todos indígenas e todos fluentemente falantes da língua kaingang. Ela acolhe em torno de 80 alunos todos os dias, desde educação infantil até o $9^{\circ}$ ano do ensino fundamental. Os turnos e horários não são muito diferentes. Funciona regularmente, de segunda a sexta-feira, nos dois turnos, exceto quando acontece uma reunião na comunidade, um evento durante a semana ou em caso de velório (o respeito é extremamente importante e as aulas param por um ou dois dias, dependendo da pessoa que tenha morrido). A solidariedade das famílias e da escola é bem complexa. Desse modo, os feriados não indígenas são respeitados pela escola, mas as pessoas realizam suas atividades cotidianas normalmente na comunidade, como, por exemplo: trabalhar na lavoura, confeccionar artesanatos, caçar na mata, coletar materiais na mata e outras atividades de costume local.

Uma professora indígena kaingang, que atua nessa escola, conta que a alfabetização acontece na língua materna e que começa na educação infantil até a metade do $2^{\circ}$ ano dos anos iniciais do ensino fundamental. A partir disso começa a introdução do português na forma oral e um pouco de escrita. O português é mais reforçado no $3^{\circ}$ ano. Mas as aulas na língua kaingang continuam até o $9^{\circ}$ ano, para que ela não se enfraqueça na pratica das crianças e jovens, tanto na escrita como na oralidade. A mesma professora também trabalha por área, nos anos finais do ensino fundamental ( $6^{\circ}$ ao $9^{\circ}$ ano). As disciplinas são: valores culturais; artes; técnicas agrícolas e kaingang. Os conteúdos das disciplinas são trabalhados em kaingang e português, pois a formação da professora é bilíngue. Sobre a mesma ideia, escreve a autora Juracilda Veiga: "a alfabetização na língua materna e o ensino da segunda língua devem ser instrumentos básicos para que os indígenas sejam eles mesmos, mantenham a sua identidade étnica e adquiram autoconfiança para sua própria libertação" (VEIGA \& SALANOVA, 2001, p. 165). 
A organização dos professores que trabalham na escola chama muita atenção, pois são bem atuantes e durante o trimestre cada turma trabalha um tema. No final do trimestre eles marcam um dia na escola para chamarem todos os pais, os kófa e a liderança, com objetivo de apresentar o que foi trabalhado naquele trimestre com as crianças, de modo que as famílias são visivelmente beneficiadas com os resultados da escola.

Os trabalhos são apresentados em forma de seminário, cartazes, teatro, danças, músicas, cantos e outros relacionados à cultura indígena ou não indígena. Os pais dos alunos são acostumados com este trabalho dos professores e a cada trimestre, para eles, é uma novidade. São parte do espaço educativo e da construção do conhecimento.

O compartilhar é próprio do costume kaingang, e a escola está desenvolvendo esta função em sua metodologia de trabalho. É assim que se mantém a tradição de nossos ancestrais na formação, com essas expectativas de ser sempre o que somos, respeitando uns aos outros dentro da formação da grande família kaingang.

A implantação da escola como um modelo de educação voltada ao pensamento europeu foi elaborada para terminar com o índio, mas isso não aconteceu e atualmente ela é a força para revitalizar a cultura tradicional (SILVA, 2020).

No caso desta escola, percebemos que a formação a partir dos costumes tradicionais está bem presente no cotidiano, pois as crianças e os jovens demostram isso, respeitando uns aos outros dentro do grande círculo de parentesco, de modo que seja bem cuidado o que resta de patrimônio de nossos ancestrais dentro de um mundo cheio de diferenças. A educação na concepção kaingang é o princípio de toda uma preparação, de uma formação do ser humano. A incorporação dessa concepção na educação escolar é destacada por Claudino.

Assim poderemos saber que a partir do momento em que começarmos a incorporar estes conhecimentos em nossos currículos escolares teremos a certeza de que a educação escolar específica e diferenciada estará realmente sendo recriada, para auxiliar a pessoa kaingang na continuação do saber coletivo e também na manutenção da cultura e da tradição. (CLAUDINO, 2013, p. 26).

Na comunidade estudada, percebemos que há uma ligação muito forte da educação tradicional kaingang com a natureza. Os rapazes sabem fazer o que aprendem com seus avôs e seus pais, como, por exemplo, a pratica de coletar mel na mata, a forma de caçar na época e lua certa, a coleta de material para confeccionar artesanatos. Sabem em qual lua isso deve ser feito, sabem preparar pequenas lavouras e plantar sementes na lua certa, a quantidade e o tamanho certo.

a preocupação é preparar a geração para a continuidade da existência cultural dessa sociedade, através dos 
ensinamentos. $E$ isso se mostra através das atitudes dos novos hoje, que mais tarde serão os grandes conhecedores que irão passar as próximas gerações. Eles serão a continuidade desse patrimônio cultural de nossos ancestrais, vai ser a continuidade do povo, da cultura e dos costumes (SILVA, 2020, p. 41).

Toda cosmologia está interligada na educação kaingang. Tudo que é ensinado de uma geração à outra está relacionado aos agentes da natureza, à paz e harmonia do bem viver, à proteção dos espíritos, aos animais e suas contribuições para lembrar a época e o tempo certo para realizar tais atividades ou tomar cuidado com relação a algumas situações cotidianas. A mesma ideia é destacada por Giannini: "A ideia de natureza é algo específico de uma dada sociedade, isto é, ela depende da forma como uma sociedade humana recorta o mundo natural como sendo 'da natureza"” (GIANNINI apud SILVA, 1994, p. 145).

Fica claro que a realidade kaingang é viver em liberdade com a natureza, não há separação entre ela e a vida humana, pois uma depende da outra. No passado todo o alimento vinha por meio dos componentes naturais, quando o relacionamento entre o ser humano e a natureza era muito forte. Nessa mesma perspectiva recente, a pesquisa relata:

A forma como o Kaingang interage com esses elementos se produz um grande conhecimento, aprendizagens riquíssimas, pois a educação tradicional está interligada com a natureza, ao mundo cosmológico que dá sentido à vida. Nesse sentido, a educação kaingang preocupa-se com a reflexão dos acontecimentos no passar do tempo, enriquecida pela vida e pelos saberes tradicionais no contato com a natureza, pois uma depende da outra. $\mathrm{E}$ essa reciprocidade de vivência entre o kaingang e a natureza, como também a espiritualidade, têm muito a ver com esse processo do ensinar e a aprendizagem com o coletivo (SILVA, 2020, p. 37).

Percebemos que a escola indígena observada está contribuindo com isso através da dedicação dos professores indígenas e não indígenas que nela atuam.

É um processo contínuo. Há sempre algo a contribuir na organização tradicional. Compreendemos que a concepção dentro da cultura é formar uma sociedade justa, com sabedoria própria de sobrevivência, formar uma geração contínua com coragem, determinação em tomar suas decisões no coletivo, que não se deixa oprimir pelo seu inimigo, com responsabilidade pela manutenção de seus costumes, da língua e do uso da natureza como mantenedora dos mantimentos. E esta comunidade mostra isso através do modo de vida e das atitudes tanto dentro como fora da escola.

Os conhecimentos transmitidos para as crianças são saberes que perpassam gerações milenares desde a sua origem e ao longo de toda sua história. Lembrando o papel desempenhado por eles através dos kófa, 
atingem uma dimensão dentro dos costumes tradicionais: a capacidade para tomar decisões a respeito de suas ações ao transmitir ensinamentos para que a educação pudesse dar estrutura à moral da existência dessa sociedade; preparar os futuros agentes dessa geração para enfrentar os desafios encontrados na longa trajetória da vida; e também adquirir confiança de todos de seu grupo e dos mais velhos, mostrando sua capacidade em ajudá-los em qualquer situação.

Então, formar crianças, jovens e adultos saudáveis é o caminho para formar uma sociedade forte e sadia em todos os sentidos. Na cultura kaingang, isso não acontece em qualquer tipo de educação, mas naquela educação transmitida através das palavras na hora certa e no momento certo. Segundo ela, as crianças, assim como os jovens e os adultos também, são reconhecidas dependendo da sua marca kamẽ e kanhrukrẽ. Os alunos da escola Katiu Gria souberam explicar sobre os remédios do mato e sua utilidade dependendo de sua marca, mas também me explicaram como se joga com as bolinhas de gude, como se ganha o jogo, souberam me ensinar como fazer armadilha para pegar a saracura na beira do rio, explicaram como funcionam os joguinhos no celular. Então percebemos que a escola, junto com as famílias, além de ensinar a ler e escrever, também os está preparando para observar o mundo ao seu redor. A compreensão dos diferentes mundos e culturas fica bem claro na cabeça deles. Não é uma educação isolada, mas uma educação com vários caminhos abertos por onde se busca o conhecimento.

Para compreendermos a escola, as ressignificações que nela podem ocorrer e os possíveis "encontros entre mundos", temos a convicção de que é necessário compreender como as crianças aprendem, ou seja: os processos próprios de aprendizagem que são acionados para formar a pessoa (BERGAMASCHI \& MENEZES, 2016, p. 744).

No entanto, há uma relação muito grande entre a liberdade e autonomia das crianças para o desenvolvimento da aprendizagem, que são as brincadeiras - como nadar no rio que fica próximo à escola onde também acontece a pratica da pescaria pelas pessoas da comunidade. Outra atividade de brincar que se faz bem presente é subir em árvores. As crianças se balançavam, se penduravam nos galhos sem muita preocupação dos pais, pois todos são responsáveis em cuidar um do outro, ou seja, os irmãos mais velhos cuidam dos mais novos. As crianças Kaingang crescem e se tornam adultas, brincando, imitando os pais, ouvindo histórias que os mais velhos contam, participando das atividades cotidianas de seu grupo. Brincam nas árvores, penduram-se em cipós, são totalmente integradas ao meio ambiente que lhes é familiar. A atitude dos pais e dos mais velhos é sempre de grande tolerância, paciência, atenção e respeito às suas peculiaridades. Desde cedo, as crianças aprendem as regras do jogo social, mesmo os pais sendo os responsáveis mais diretos pela criação dos filhos. As crianças são integradas à vida comunitária, 
aprendendo o que pode e o que não pode ser feito, como explica Gonçalves (2011).

Essas atividades lhes proporcionam a aquisição de habilidades e também a superação das dificuldades e das facilidades do dia a dia na comunidade. Por isso, as crianças são livres, mas também cuidadas por todos que fazem parte da comunidade, pois, nos costumes kaingang, todos são parentes em respeito às duas metades kaingang: kamẽ e kanhrukrẽ.

Porém, percebemos que há desafios que eles vêm enfrentando e, de alguma forma, ainda os ameaçam. Atualmente, estão convivendo com um modelo de autoritarismo religioso, especialmente através das igrejas neopentecostais, que proíbe muitas coisas importantes em suas práticas tradicionais e rituais, pois quem segue a religiosidade imposta pelo não índio deve seguir um conjunto de princípios e procedimentos. Em uma pesquisa recente (SILVA, 2020), um dos entrevistados deixa claro a mesma afirmação:

Tudo começou pelos padres jesuítas que tinham como papel fundamental catequizar os índios dizendo que a religião católica era a única e verdadeira que eles tinham que obedecer e seguir os ensinamentos escrito na Bíblia, tentando mudar assim o costume e a mentalidade do kanhgág. Meu pai conta que houve profundas transformações, pois os kaingang eram obrigados a abandonar suas crenças, suas ordens e ensinou o índio a seguir seu regime (SILVA, 2020, p. 51).

Mas isso, não quer dizer que estão desistindo, mas apenas se mostram preocupados com a futura geração. Aqui, essa escola tem entrado com todo o reforço da cultura tradicional pelos professores e pelos kófa que compõem esta comunidade.

Nessa perspectiva de convivência entre os dois modos de vida (indígena e não indígena), de alguma forma eles têm ajudado a manter força em defender o que é seu por direito. Pelo que compreendemos, estão aprendendo a utilizar alguns modelos impostos pelo não indígena como um mecanismo de reforçar esses conhecimentos da ancestralidade.

Um desses modelos é a escola, que atualmente é uma escola indígena reconhecida pelo Estado que segue uma metodologia escolhida pelos indígenas e trabalha muito a questão da revitalização da cultura, mas sempre relacionando ao pensamento do mundo não indígena. $O$ papel dela, atualmente, é trazer para sala de aula os conhecimentos tradicionais, através dos professores que nela trabalham, através de métodos específicos em seus planejamentos. Assim também como a língua materna que está bem fortalecida na pratica e na escrita, além da língua portuguesa. Hoje ela é compreendida como a arma de defesa de seus direitos garantidos na lei.

A educação escolar indígena, com sua especificidade, vem evoluindo, sendo relevante na vida dos kaingang, pois contribui nesse processo do ensinar especificando como agir em determinadas situações 
que estejam em confronto com a cultura tradicional. É possível observar isso nas atitudes das crianças na comunidade e nos jovens indígenas que conseguem entrar em diversos cursos fora da Terra Indígena. Seja no ensino médio, cursos técnicos, curso normal (magistério), cursos de informática, e também em universidades, pois sempre estão defendendo seu ponto de vista, suas ideias e opiniões para melhoria da educação e a continuidade da cultura e dos costumes kaingang.

\section{Considerações Finais}

Atualmente, vemos em uma sociedade onde um quer ser melhor que outro em seu projeto de vida. A educação parece não ser mais aquela arma poderosa que faz a pessoa se sentir comprometida com a coletividade. Aquela que transforma, que prepara, que forma o ser humano em ser humano.

O mundo atual está dominado por um pensamento mais capitalista e isso está desestruturando a convivência do bem viver e do bem estar em sociedade, assim como também na política brasileira. Mesmo assim, a cultura indígena kaingang tem superado os desafios, como presenciamos no decorrer de nossa pesquisa junto à escola estudada. A educação tradicional, a língua de uma sociedade é a arma fundamental para a defesa de seus direitos, diante das situações na atualidade. Procuramos compreender a realidade social desta comunidade, em sua maneira de viver e educar se, como também a educação escolar. Observamos o entrelaçamento desses dois modos de educar.

Assim, analisando a própria trajetória como estudante, professora e, agora, pesquisadora, verificamos a construção e reconstrução de uma cultura que muitos dizem ser inferior, mas que, na verdade, é apenas diferente. Conforme citado anteriormente, o povo kaingang, dentro da terra indígena, possui uma organização social própria e fora dela conhece sua identidade, o sentido de liberdade e autonomia em buscar seus direitos garantidos pela lei. A escola aqui estudada é um exemplo de escola indígena que está preparando para isso. Para que não haja negação da identidade pela futura geração, mas que seja demostrada a verdadeira identidade através dos seus atos de reconhecimento cultural, mesmo em uma sociedade em que as pessoas demostram, muitas vezes, se importar apenas em ter. Algo diferente para o kaingang, mas que esse povo aprendeu a conviver. Assim também como as mudanças e transformações, que vêm acontecendo desde séculos passados em seu modo de viver.

$\mathrm{Na}$ forma de transmitir conhecimentos, dentro da educação tradicional, aquela pensada pelos nossos ancestrais, na formação da família, convivência na coletividade, comunicação entre parentesco e na reprodução pensada para dar continuidade a uma geração pura e saudável, o povo kaingang tem aprendido a produzir alguns alimentos conforme a necessidade, ou seja, criou em seu pensamento um sistema de convivência junto à sociedade não indígena, conforme sua cultura e 
costumes na realidade, dissociando as que são reconhecidas pela Constituição Federal.

Nesta trajetória de pesquisa observamos que nessa comunidade o bem estar é ficar com a família, cuidar um do outro no grupo de parentesco, pois para isso foram educados pelos seus ancestrais. São riquezas da cultura que precisam ser preservadas e conservadas, assim como esta comunidade está se desenvolvendo. Esse comportamento se faz muito presente na cultura kaingang. Quando alguém da família se afasta por um tempo, causa um desespero para todos. É um costume: os filhos não podem se afastar dos pais, dos avós, senão eles ficam doentes. O bem viver é estar todos juntos, compartilhando tudo com seus cunhados, seus irmãos e primos. Estar de bem com a natureza e suas riquezas, desenvolvendo seus afazeres cotidianos conforme as necessidades.

O que observamos é que a educação escolar, ainda que tenha sido inserida pelos não índios (fog), pode concretamente contribuir para a solidificação da cultura kaingang desde que se integre à educação kaingang, assumindo seus valores, no sentido apontado por Durkheim, que afirma que "cada sociedade possui um sistema de educação que se impõe aos indivíduos de modo geralmente irresistível" (DURKHEIM, apud TASSINARI, 2015, p. 143). 


\section{Referências bibliográficas}

BERGAMASCHI, Maria Aparecida; MENEZES, Ana Luisa Teixeira. Crianças indígenas, educação, escola e interculturalidade. Revista e-Curriculum, São Paulo, v.14, n.02, p. 741 - 764, abr./jun. 2016.

BRASIL. Referencial curricular nacional para as escola indígenas. Brasilia: MEC/SEF, 1998.

CLAUDINO, Zaqueu Kej. A formação da pessoa nos pressupostos da tradição, Educação Indigenas Kaingang. Dissertação (Mestrado em Educação) - PPGEDU, Universidade Federal do Rio Grande do Sul, Porto Alegre, 2013.

FAUSTINO, Rosangela Celia; MOTA, Lucio Tadeu. Crianças indígenas: o papel dos jogos, das brincadeiras e da imitação na aprendizagem e no desenvolvimento. Acta Scientiarum Maringá, v. 38, n. 4, p. 395-404, out./dez. 2016

FERREIRA, Bruno. Educação Kaingang: processos próprios de aprendizagem e educação escolar. Dissertação (Mestrado em Educação) - PPGEDU, Universidade Federal do Rio Grande do Sul, Porto Alegre, 2014.

FREITAS, Maria Inês de. Escola Kaingang concepção cosmo-sócio-políticas e práticas cotidianas. Dissertação (Mestrado em Educação) - PPGEDU, Universidade Federal do Rio Grande do Sul, Porto Alegre, 2017.

FREIRE, Paulo. Pedagogia do oprimido. Rio de Janeiro/São Paulo: Paz e Terra, 2018.

GONÇALVES, L. M. C. Crianças indígenas Kaingang em escola não indígena: um estudo de caso envolvendo a Escola Estadual de Ensino Fundamental Manuel Bandeira, em Lajeado/RS. 2011. 74 f. Monografia (Especialização em Supervisão e Gestão Educacional) - Centro Universitário Univates, Lajeado, 2011.

IBGE. Indígenas. https://indigenas.ibge.gov.br/estudos-especiais-3/o-brasilindigena/povos-etnias.html. Acesso em 6 jan. 2020.

LAROQUE, Luís Fernando da Silva and SILVA, Juciane Beatriz Sehn da. Ambiente e cultura Kaingang: saúde e educação na pauta das lutas e conquistas dos Kaingang de uma terra indígena. Educação em Revista, v.29, n.2, p.253-275, jun 2013.

SILVA, Ivone jagnigri da. Mỹ ge ke kanhgág jykre pẽ ki - Educação na concepção kaingang. Dissertação (Mestrado em Educação) - PPGEDU, Universidade Federal do Rio Grande do Sul, Porto Alegre, 2020.

SILVA, Sergio Baptista. Dualismo e cosmologia kaingang: o xamã e o domínio da floresta. Horizontes Antropológicos. Porto Alegre, v.8 n.18, p. 189-209, dez. 2002

TASSINARI, Antonella. Produzindo corpos ativos: a aprendizagem de crianças indígenas e agricultoras através da participação nas atividades produtivas familiares. Horizontes Antropológicos, v.21, n.44, p.141-172, jul./dez. 2015. 
VEIGA, Juracilda. Revisão bibliográfica crítica sobre organização kaingang. Cadernos do CEOM v, 6 n. 8, 1992.

VEIGA, Juracilda \& SALANOVA, Andrès (Orgs.) Questões de educação escolar indígena: da formação do professor ao projeto de escola. Brasìlia: FUNAI/DEDOC, Campinas/ALB, 2001.

Recebido em: 24/02/2020* Aprovado em: 25/06/2020 * Publicado em: 16/12/2020 